\title{
Clinical recommendations to guide physical therapy practice for Huntington disease
}

Lori Quinn, EdD, PT, Deb Kegelmeyer, MS, PT, DPT, GCS, Anne Kloos, PhD, PT, NCS, Ashwini K. Rao, EdD, OTR/L, FAOTA, Monica Busse, BSc, BSc (Hons) MSc (Med) PhD, PT, and Nora E. Fritz, PhD, PT, DPT, NCS

Neurology ${ }^{\circledR}$ 2020;94:217-228. doi:10.1212/WNL.0000000000008887

\author{
Correspondence \\ Dr. Fritz \\ nora.fritz@wayne.edu
}

\begin{abstract}
Objective

In the past decade, an increasing number of studies have examined the efficacy of physical therapy interventions in people with Huntington disease (HD).

\section{Methods}

We performed a mixed-methods systematic review using Joanna Briggs Institute (JBI) methodology and included experimental and observational study designs. The search resulted in 23 quantitative studies and 3 qualitative studies from which we extracted data using JBI standardized extraction tools. Results of this review suggested that physical therapy interventions may improve motor impairments and activity limitations in people with HD. Here, we expand on the review findings to provide specific recommendations to guide clinical practice.
\end{abstract}

\section{Results}

We recommend the following specific physical therapy interventions for people with HD: aerobic exercise (grade A evidence), alone or in combination with resistance training to improve fitness and motor function, and supervised gait training (grade A evidence) to improve spatiotemporal features of gait. In addition, there is weak (grade B) evidence that exercise training improves balance but does not show a reduction in the frequency of falls; inspiratory and expiratory training improves breathing function and capacity; and training of transfers, getting up from the floor, and providing strategies to caregivers for involvement in physical activity in the midstages of HD may improve performance. There is expert consensus for the use of positioning devices, seating adaptations, and caregiver training in late stages of HD.

\section{Conclusions}

There is strong evidence to support physical therapy interventions to improve fitness, motor function, and gait in persons with HD. 


\section{Glossary}

EHDN = European Huntington Disease Network; HD = Huntington disease; HSG $=$ Huntington Study Group.

This clinical practice guideline provides clinical recommendations for physical therapy interventions and patientreported outcomes for individuals with Huntington disease (HD). The target audience are rehabilitation professionals and referring physicians providing care to persons with HD. The recommendations should be interpreted by the clinician in the context of their specific clinical practice and the patient's impairments, goals, and disease stage, while considering the potential for harm.

We used the Joanna Briggs Institute (JBI) method for critical appraisal of research, assignment of evidence to the literature, and assignment of levels of strength to the recommendation. The JBI method allows for inclusion of experimental study designs other than randomized controlled trial, such as observational study designs, retrospective and prospective cohort studies, expert consensus, and qualitative studies. The inclusion of a wide range of study designs (i.e., all levels of evidence) was critical, given the paucity of randomized controlled trials involving physical therapy in HD. The guideline is organized according to the level of evidence and the grade of the recommendation (tables 1 and 2) underpinning action statements. A summary of action statements, a description of each action statement, and research recommendations are provided.

Each individual article was graded based on the 2011 JBI criteria to determine the level of evidence of each study design $(\text { table } 1)^{1}$ and the grade of the recommendation (table 2$)^{2}$ JBI tools were developed by experts in the field, piloted, reviewed, and then approved by the JBI Scientific Committee.
Levels 1 and 2 differentiate stronger from weaker studies using key questions. The grade represents the overall strength of the evidence available to support the action statement. Each action statement is preceded by a letter grade to indicate the strength of the recommendation, followed by a summary of the supporting evidence. A grade of A could be seen as aligning with "Strong" recommendations in GRADE, and a grade B could be seen as aligning with "Weak" or "Conditional" recommendations in GRADE. Action statements preceded by a dash $(-)$ indicate actions based primarily on expert opinion.

\section{Introduction}

In 2009, the Physiotherapy Working Group of the European Huntington Disease Network (EHDN) developed an evidencebased Clinical Guidance Document to inform optimal physical therapy management of people with $\mathrm{HD}$ and facilitate uniformity of care internationally. ${ }^{3}$ Given the limited evidence at the time, this document was largely based on expert opinion. Seven treatment-based classifications were developed to facilitate translation of guidelines into clinical practice. These classifications provided a framework for management of the range of impairments and activity limitations across the disease stages. Since 2012, an increasing number of studies have examined the feasibility and efficacy of physical therapy interventions to improve physical function, mobility, cognition, mood, and quality of life in individuals with HD. In 2017, the Guidance Document was revised to incorporate the new literature within a concise, user-friendly Clinical Practice Guideline.

Table 1 Levels of evidence

\begin{tabular}{|c|c|c|}
\hline Level & Sublevel & Description \\
\hline \multirow[t]{4}{*}{ 1: Experimental designs } & A & Systematic review of randomized controlled trials (RCTs) \\
\hline & $\mathrm{B}$ & Systematic review of RCTs and other study designs \\
\hline & $\mathrm{C}$ & $\mathrm{RCT}$ \\
\hline & $\mathrm{D}$ & Pseudo-RCT \\
\hline \multirow[t]{4}{*}{ 2: Quasi-experimental designs } & A & Systematic review of quasi-experimental designs \\
\hline & $\mathrm{B}$ & Systematic review of quasi-experimental designs and other lower study designs \\
\hline & $\mathrm{C}$ & Quasi-experimental prospectively controlled study \\
\hline & D & Pretest-posttest or historic/retrospective control group study \\
\hline \multirow[t]{5}{*}{ 3: Observational-analytic designs } & A & Systematic review of comparable cohort studies \\
\hline & B & Systematic review of comparable cohort and other lower study designs \\
\hline & $\mathrm{C}$ & Cohort study with a control group \\
\hline & $\mathrm{D}$ & Case-control study \\
\hline & $\mathrm{E}$ & Observational study without a control group \\
\hline \multirow[t]{4}{*}{ 4: Observational-descriptive studies } & A & Systematic review of descriptive studies \\
\hline & B & Cross-sectional study \\
\hline & $\mathrm{C}$ & Case series \\
\hline & D & Case study \\
\hline \multirow[t]{3}{*}{ 5: Expert opinion and bench research } & A & Systematic review of expert opinion \\
\hline & B & Expert consensus \\
\hline & $\mathrm{C}$ & Bench research/single expert design \\
\hline
\end{tabular}


Table 2 Grades of recommendations

\begin{tabular}{lll}
\hline Grade & Recommendation & Strength of recommendation \\
\hline A & Strong & $\begin{array}{l}\text { It is clear that the desirable effects outweigh the undesirable effects } \\
\text { There is evidence of adequate quality supporting the use of the strategy } \\
\text { There is a benefit or no impact on resource use } \\
\text { Values, preferences, and the patient have been taken into account }\end{array}$ \\
\hline B & Weak & $\begin{array}{l}\text { Desirable effects appear to outweigh the undesirable effects, but it is not clear } \\
\text { There is evidence supporting the use of the strategy, although it may not be of high quality } \\
\text { There is a benefit, no impact, or minimal impact on resource use } \\
\text { Values, preferences, and the patient may or may not have been taken into account }\end{array}$ \\
\hline
\end{tabular}

Individuals with HD develop physical, cognitive, and psychological impairments that negatively affect their mobility and participation in life activities and that ultimately reduce quality of life. ${ }^{4}$ Cognitive and psychological impairments manifest early in the disease. Mobility is negatively affected by key impairments of chorea, dystonia, and bradykinesia somewhat later. ${ }^{3,4}$ Physical therapy encompasses a multitude of interventions ranging from exercise and physical activity promotion for people to gait and balance training and ultimately respiratory and palliative care as the disease progresses. A treatment-based classification, which is organized around impairments and activity limitations across disease stages, provides a framework for the current guidelines. As such, these guidelines encompass a range of physical therapy outcomes (gait, balance, and quality of life) and a range of physical therapy interventions (exercise, physical activity, balance and task-specific training, and respiratory training). Given the paucity of evidence available for any specific physical therapy intervention on any specific outcome, we believe that this approach is most pragmatic and will yield optimal benefit of providing guidelines to support evidence-based physical therapy intervention in people with HD.

A systematic review of the literature to determine that evidence exists to support exercise and physical therapy as a means to address impairments and activity limitations present in HD informed these guidelines. ${ }^{5}$ Of 20 articles that met the inclusion criteria, the evidence provided preliminary support for physical therapy interventions for improving motor function, gait speed, balance, and a range of physical and social patient-reported outcomes. The authors discussed the results in terms of application to 7 treatment-based classifications to assist physical therapy treatment planning in HD. ${ }^{6,7}$

The guideline is designed to answer the following PICO question: for individuals with HD (all stages) across practice settings, what is the effect of physical therapy interventions (e.g., exercise, physical activity interventions, task-specific training, gait and balance training, and respiratory training) on outcomes of mobility, balance, physical fitness, physical activity, respiratory function, and patient-reported outcomes compared with no intervention, wait list control, or social contact control?

\section{Statement of intent}

The target users of this guideline are physical therapists and physical therapist assistants. Other rehabilitation and referring physicians may also use these guidelines to support their practice or referral to physical therapy. It is not intended to serve as a legal standard of care. This guideline is a summary of practice recommendations supported by the current published literature reviewed by expert clinicians and stakeholders. Thus, the recommendations set forth herein should be considered guidelines only, not required directives. Adherence to these recommendations will not ensure a successful outcome in every patient. Clinical judgment on the part of the rehabilitation professional is critical for determining the treatment plan for the individual patient, accounting for clinical data collected from the patient, patient preferences and values, and clinician expertise and scope of practice.

\section{Methods}

In 2016, members of the Guideline Development Group were tasked by the Huntington Study Group (HSG) and the EHDN with the development of a clinical guideline for physical therapy in HD. Funding for this work was received from the Griffin Foundation, HSG, and EHDN. The workgroup solicited members to form a multidisciplinary (neurology, physical therapy, and occupational therapy) advisory board of people actively involved in management of persons with HD. The advisory board was involved with the development of the content and scope of the guideline.

\section{External review process by stakeholders}

External stakeholders were consulted throughout the process of guideline development so that views and preferences could be incorporated into the results and discussion sections. Relevant stakeholders included persons with HD and their families, physical therapists, speech therapists, neurologists, psychologists, nurses, and HD researchers.

The stakeholders reviewed the draft of the guideline that was released for public comment. Ninety-five percent $(22 / 23)$ of patient and family stakeholders felt that the guideline was definitely informative, and $100 \%$ felt that the guideline would "definitely" or "probably" be a useful resource to a physical therapist or other health care professional. In addition, 100\% 
endorsed that the guideline provided a better understanding of the specific recommendations for exercise and physical therapy in $\mathrm{HD}$ and of the role of exercise for persons with $\mathrm{HD}$.

Comments were solicited from the public via email to professional organizations and posting the complete draft of the clinical practice guideline on the Institute of Knowledge Translation web site in February 2019. The guideline was viewed 384 times with 277 downloads. This call included solicitation for feedback from consumers; applicable comments have been incorporated into the final version of the guideline. A complete draft of the guideline was reviewed by the American Academy of Neurology Board of Directors in December 2018 and affirmed the value of this guideline as an educational tool for neurologists.

\section{Literature search}

The protocol for the systematic review has been published ${ }^{8}$ and was developed using the guidelines set forth by the JBI. ${ }^{9}$ JBI tools are widely used, with more than 70 collaborating entities across 34 countries. ${ }^{10}$ The JBI tools are recognized as the most congruent for evaluating qualitative studies (Hannes 2010). The initial search included publications between January 2003 and May 2016. An updated search was performed to inform this clinical practice guideline from May 2016 to August 2018.

A research librarian from The Ohio State University (L.H.) conducted searches on the following databases: CINAHL, PEDro, MEDLINE via PubMed, Cochrane Library, Scopus, SPORTDiscus, and PsychINFO. The PICO question was framed as, "Are physical therapy interventions (i.e., exercise, physical activity interventions, and task-specific training) recommended for individuals with HD to improve mobility, balance, physical activity and patient-related outcomes across disease stages and practice settings?" The primary keywords used in the searches were: huntington* disease, physical therap*, physical activit*, exercise, and physiotherapy*. Additional text words included the specific forms of exercise and mobility intervention (see published systematic review ${ }^{5}$ ).

The initial search yielded 2,377 records that ultimately resulted in 18 quantitative articles and 2 qualitative included articles ${ }^{11-30}$; a flowchart is available in our published systematic review. ${ }^{5}$ The updated search included 5 additional quantitative articles ${ }^{31-35}$ and 1 additional qualitative article, ${ }^{36}$ resulting in a total of 23 quantitative and 3 qualitative studies reviewed. A table summarizing all quantitative studies is publicly available on aan. com/guidelines.

Included articles were those in adults with HD across stages and care settings that evaluated physical therapy interventions such as aerobic exercise, strengthening exercise, walking training, balance training, task-specific training, seating and positioning, postural alignment or respiratory interventions, and included outcomes measuring physical or cognitive function. For qualitative studies, those that examined perceptions of physical therapy for the patient, family, or caregiver using qualitative methods were included. Additional details on inclusion and exclusion criteria may be found in our published systematic review. ${ }^{5}$

\section{Critical appraisal process}

Data were extracted from the studies using the standardized JBI data extraction tools. ${ }^{9,37}$ Next, 2 authors within the guideline development group, who had been trained to use the JBI tools, independently assessed the methodologic validity before inclusion in the study, followed by verbal discussion in a group setting to resolve disagreements.

For areas where there was limited or no evidence from the literature available to guide treatment, we solicited expert opinion. A custom survey was developed to determine current treatment practices around the world for seating, secondary postural changes, and late-stage care. Respondents were asked to provide a description of specific interventions used with individuals with $\mathrm{HD}$ for each of these categories. The survey was distributed to members of the HSG, HD Centers of Excellence, Degenerative Disease Special Interest Group of the Academy of Neurologic Physical Therapy of the American Physical Therapy Association, and the Physiotherapy Working Group of the EHDN. The responses were pooled to determine consensus expert opinions for areas with limited evidence. Finally, the results were summarized in narrative format.

One hundred two individual respondents completed the survey. Of those, $74 \%$ were physical therapists, and $61 \%$ had treated individuals with HD for more than 5 years. Sixty-six percent of the respondents were from the United States, 21\% from Europe, representing 10 countries, and the remainder from Canada, Australia, Israel, and New Zealand. Forty-four percent endorsed working with individuals with $\mathrm{HD}$ in the late stage of the disease; respondents endorsed the following strategies with individuals with $\mathrm{HD}$ with end-stage disease: positioning, range of motion exercises, active movement, respiratory exercises, and education (figure 1). These recommendations are summarized as level 5B evidence in table 3.

\section{Data availability}

All data are published within this article and associated tables, figures, and supplemental data.

\section{Action statements}

Action statements are listed first with the grade of the recommendation followed by the recommendation. A standardized profile of information for each action statement is available at aan.com/guidelines. A summary of the action statements, grades of recommendation, and research recommendations is found in table 4. These 2019 guidelines are based on the literature published between January 2003 and August 2018. These guidelines will be considered for review in 2024 or sooner if new evidence becomes available. Any updates to the guideline in the interim period will be noted on the American Academy of Neurology web site: aan.com/guidelines. 
Figure $1 \mathrm{~A}$ global survey of health care providers with expertise in the treatment of individuals with late-stage HD yielded the prevalence of physical therapy interventions used

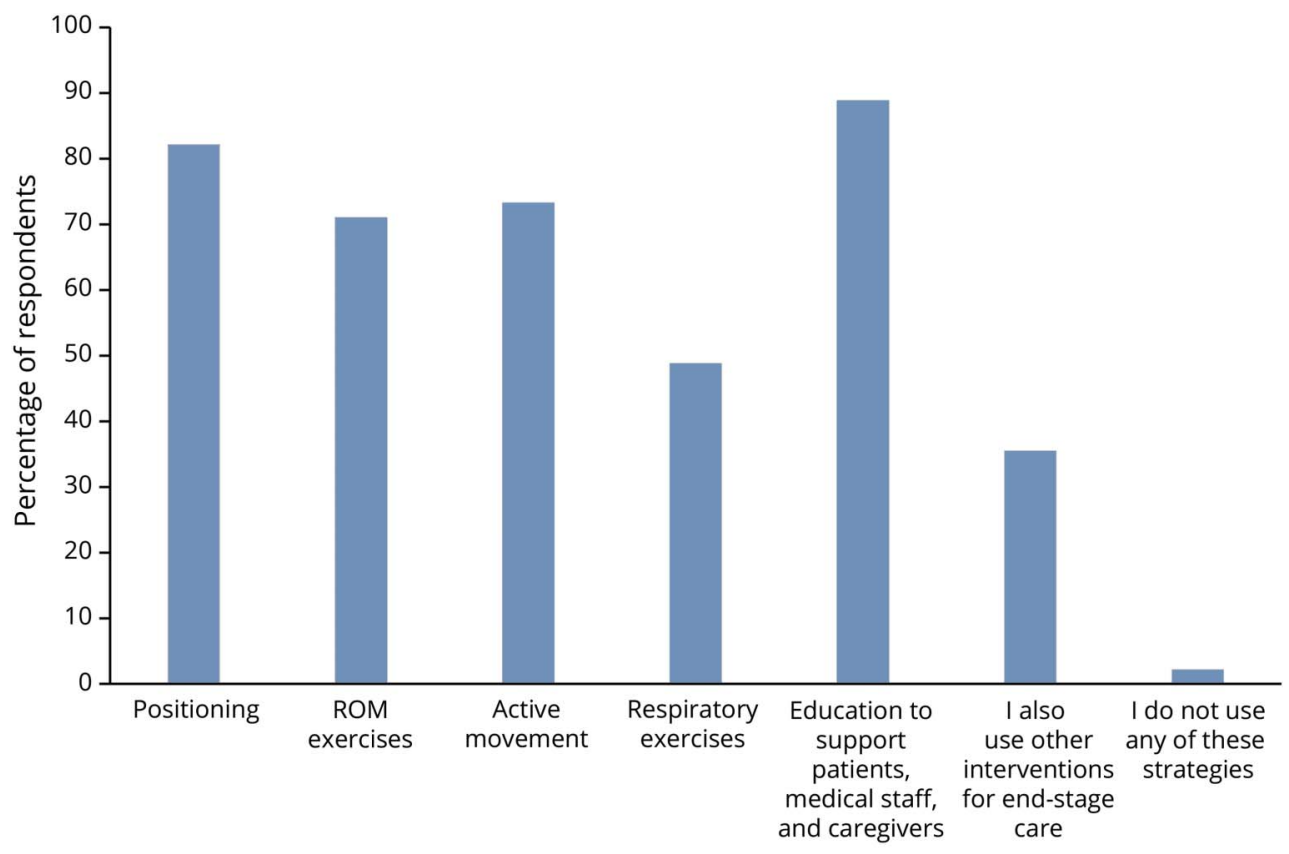

Intervention strategies used for persons with late-stage HD

Of the 102 survey respondents, 45 endorsed working with individuals with late-stage HD. Of those, $82.2 \%$ endorsed the use of positioning, $71.1 \%$ used ROM exercise, $73.3 \%$ used active movement, $48.9 \%$ included respiratory exercises, $88.9 \%$ incorporated education to support patients, medical staff, and caregivers, $35.6 \%$ reported using additional interventions for late-stage care, and only $2.2 \%$ of respondents (i.e., 1 respondent) did not use any of these strategies. $\mathrm{HD}=$ Huntington disease; ROM = range of motion.

\section{Action statement 1: Effectiveness of aerobic exercise paired with strengthening exercises in persons with HD}

Physical therapists should prescribe aerobic exercise (moderate intensity, 55\%-90\% heart rate maximum) paired with upper and lower body strengthening 3 times per week for a minimum of 12 weeks to improve fitness and to stabilize or improve motor function (evidence quality: 1-3; recommendation strength: strong).

\section{Supporting evidence and clinical interpretation}

Eight publications ${ }^{12,15,16,19,27,29,31,32}$ evaluated the impact of exercise (aerobic, strengthening, and general conditioning) and/or physical activity interventions to address a range of outcomes from 6 separate studies. Two pairs of publications ${ }^{12,15,16,29}$ included data from the same data set but evaluated different outcomes. Intervention durations were 8 weeks, ${ }^{19} 12$ weeks, ${ }^{12,16,27} 14$ weeks, ${ }^{32} 26$ weeks, ${ }^{31}$ and 9 months. ${ }^{15,29}$ Frequency of exercise ranged from 3 to 4 times per week, which included center-based and home-based exercises.

Four of the 6 studies included aerobic exercise as a component of the intervention. ${ }^{12,15,16,27,29,31}$ Exercise intensity varied from 55\% to $90 \% \mathrm{VO}_{2}$ max (based on actual $\mathrm{VO}_{2}$ max or age-predicted values), and duration ranged from 10 to 30 minutes (median duration $=25$ minutes). Four studies incorporated strengthening and general conditioning exercises, involving core, upper body, and lower body musculature. ${ }^{12,15,16,19,27,29}$ Four studies ${ }^{12,16,19,32}$ used a progressive home walking program (average once per week). Two studies ${ }^{20,32}$ incorporated use of an exercise DVD specific to persons with $\mathrm{HD}$ that included balance and circuit training, strengthening, flexibility, and relaxation exercises.

\section{Action statement 2: Effectiveness of gait training in persons with HD}

Physical therapists should prescribe one-on-one supervised gait training to improve spatiotemporal measures of gait (e.g., walking speed and step length) (evidence quality: 1-4; recommendation strength: strong).

\section{Supporting evidence and clinical interpretation}

Fourteen studies examined the effects of exercise programs on clinical and mobility measures. Six randomized controlled trials (level 1C) examined the use of exercise in outpatient, home, and gym settings to improve mobility. All studies provided individual supervision, and transportation was provided for the one gym-based study. Interventions to improve mobility included gait and transfer training, ${ }^{26}$ stationary cycling with a home walking program and resistance exercise, ${ }^{12}$ use of a dance-based video game, ${ }^{21}$ home exercise with a DVD and a walking program, ${ }^{19}$ a gymbased exercise program including aerobic and resistance 
Table 3 Summary of clinical evidence

\section{Category and description of primary movement impairments}

\section{Exercise capacity and/or physical activity}

Absence of or limited motor impairment in functional activities; potential for cognitive and/or behavioral issues. Focus is on prevention of future movement system impairments

\section{Available \\ levels of Summary of evidence (includes primary \\ evidence interventions and outcomes)}

$1 C^{12,19,27,31,32}$

$1 D^{29}$

$2 \mathrm{D}^{15}$

$3 \mathrm{E}^{16}$
Primary interventions: aerobic exercise (55\%-90\% age-predicted heart rate maximum) and resistance exercise (upper and lower body, core) 3-4 times per week (minimum of 12 weeks for fitness and motor function benefits); home-based exercise and walking programs

Setting: home, outpatient

Primary outcomes: motor function (UHDRS total motor or modified motor), fitness ( $\mathrm{VO}_{2}$ max)

Secondary outcomes: physical performance test, six-minute walk test, Lorig Self-Efficacy for Exercise, physical activity (measured by pedometers or the International Physical Activity Questionnaire), Berg Balance Scale, gait speed, quality of life, and cognitive tests.

\section{Mobility and function}

Impairments in strength or fatigue resulting in mobility limitations; slow gait

$1 C^{12,19,21,26,27,35}$
$2 D^{11,13,23-25,30}$
$3 E^{22,34}$
$4 C^{14}$

Primary interventions: task-specific training of walking and transfers; multidisciplinary rehabilitation

Setting: inpatient, outpatient, home, supervised at gym

Primary outcomes: gait speed, Timed Up and Go, spatiotemporal measures of gait, and ten-meter walk test

Secondary outcomes: balance (Romberg, Berg Balance Scale, functional reach test, Pastor test, and four square step test) and balance confidence (ABC Scale)

\section{Balance and falls risk}

Impairments in balance; increased falls risk

$1 C^{12,21,26,29}$
$2 D^{11,23-25}$
$4 C^{14,33}$

Primary interventions: task-specific training of balance; multidisciplinary rehabilitation

Setting: outpatient clinic, inpatient rehabilitation hospital, community, and home settings

Primary outcomes: none

Secondary outcomes: balance (Romberg, Berg Balance Scale, functional reach test, Pastor test, and four square step test), balance confidence (ABC Scale); Goal Attainment Scaling

\section{Respiratory function}

Impaired respiratory function and capacity, limited endurance, and/or airway clearance, resulting in restrictions in functional activities and risk for infection

\section{$1 C^{28}$}

$1 \mathrm{D}^{18}$

5B Consensus

of expert

opinion survey

Primary interventions: inspiratory and expiratory training, with and without resistance.

Setting: home

Primary outcomes: respiratory muscle strength, cough effectiveness Secondary outcomes: swallowing, breathlessness, exercise capacity/ endurance

\section{Secondary musculoskeletal and postural changes}

Musculoskeletal and/or respiratory changes resulting in physical deconditioning and subsequent decreased participation in daily living activities or social/work environments.

Altered alignment in sitting or standing due to secondary adaptive changes, involuntary movements, muscle weakness, and incoordination resulting in limitations in functional activities in sitting or standing

\section{End stage}

Active or passive range of motion limitations and poor active movement control resulting in inability to ambulate; dependent for most ADLs; difficulty maintaining upright sitting posture

\section{$2 \mathrm{D}^{11,13}$}

5B Consensus of expert

opinion survey
Primary interventions: transfer training, postural stability training Setting: outpatient, inpatient rehabilitation

Primary outcomes: gait (double support \%, stride length, and gait speed), force plate (length and speed of center of mass projection), physical performance test, and Tinetti mobility test Secondary outcomes: Berg Balance Scale, Timed Up and Go, Barthe Index, and UHDRS Total Functional Capacity Scale

\section{$5 B$ Consensus of expert opinion survey Primary interventions: multisensory stimulation, hydrotherapy, and video-based exercise \\ Setting: home, specialized unit for late-stage HD \\ Primary outcomes: behavior Mood Disturbance Scale; quality of life measures \\ Secondary outcomes: blood pressure, heart rate, and respiratory rate}

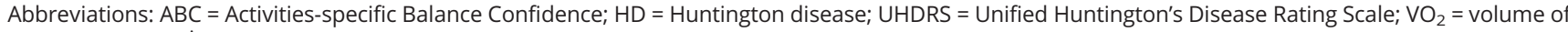
oxygen consumption.

exercise, $^{27}$ and an outpatient-based multidisciplinary intervention of supervised aerobic and resistance training. ${ }^{35}$ Gait speed (measured with the 10-meter walk test [10MWT]) improved after use of a DVD for home exercise and a walking program delivered 3 times a week over 8 weeks $^{19}$ and following 36 weeks of gait and resistance training. ${ }^{35}$ Gait speed did not improve in the home-based, task-specific exercise program, but all participant-directed gait-related goals were met. ${ }^{26}$ The gym-based aerobic and resistance training program, a feasibility study, and dance- based video game play, which did not incorporate walking training, did not improve gait speed. ${ }^{21,27}$ The gym-based therapy was completed by $82 \%$ of participants, but only 7 of the clients achieved the expected 150 minutes of moderate exercise per week. ${ }^{27}$ The dance-based video game led to a decrease in double support percent of gait cycle during forward and backward walking. ${ }^{21}$ Mobility measures that did not demonstrate significant improvement in any study were the 30 -second chair stand test, ${ }^{12}$ step time, and step time coefficient of variation. ${ }^{19,21}$ 
Table 4 Summary of action statements and research recommendations

Action statement
Effectiveness of aerobic exercise paired with strengthening
exercises in persons with Huntington disease: physical
therapists should prescribe aerobic exercise (moderate
intensity, $55 \%-90 \%$ heart rate maximum) paired with upper
and lower body strengthening 3 times per week for
a minimum of 12 weeks to improve fitness and to stabilize or
improve motor function.

Effectiveness of gait training in persons with Huntington disease: physical therapists should prescribe one-on-one supervised gait training to improve spatiotemporal measures of gait.

Grade of

\title{
recommendation Research recommendations
}

A

Researchers should conduct larger-scale clinical trials to determine the efficacy of aerobic and strengthening intervention on motor function and disease progression. In addition, studies should address optimal frequency, intensity, and timing of interventions.
Researchers should conduct larger-scale clinical trials to determine the efficacy of different gait training interventions (overground, treadmill, and other) on gait kinematics and kinetics across stages of the disease. In addition, studies should address optimal frequency, intensity, and timing of interventions.

\section{Effectiveness of balance exercises in persons with Huntington disease: physical therapists may prescribe individualized exercises, including balance exercises, delivered at a moderate frequency and intensity to improve balance and balance confidence.}

B

Researchers should conduct larger-scale clinical trials that use interventions specifically focused on balance to confirm the benefits of balance training in persons with HD. Ideally, these studies should include persons with HD at all stages of the disease and be of sufficient duration to determine whether balance interventions will delay onset or decrease numbers of falls.

\section{Effectiveness of breathing exercises in persons with Huntington disease: physical therapists may provide regular breathing exercises, including inspiratory and expiratory training, to improve respiratory muscle strength and cough effectiveness.}

Effectiveness of postural control training in persons with Huntington disease: physical therapists may prescribe an individually tailored program to improve postural control and may use positioning devices to optimize posture.
B Researchers should conduct larger-scale clinical trials to confirm the benefits of respiratory training in persons with HD. Inclusion of functional testing to determine benefits on functional performance and/or participation would be useful.
No

Recommendation
Researchers should conduct larger-scale clinical trials to examine the effectiveness of postural control exercises in prevention of secondary postural changes. In addition, studies are needed to examine the effectiveness of positioning devices in improving posture, activities of daily living, and reducing caregiver burden in the advance stage of HD.

\begin{abstract}
Role of physical therapy on ADL's, seating and positioning in end-stage care of persons with Huntington disease: physical therapists should ensure that care plans for individuals with HD with end-stage disease include appropriate positioning and seating, active movement, position, respiratory exercise, and education. Family and caregiver training to provide strategies for maintaining appropriate ongoing activity and participation for as long as possible is an important focus for the physical therapy team as part of end-stage care.
\end{abstract}

No recommendation
Researchers should conduct longitudinal evaluations of endstage care in HD. Qualitative and mixed-methods approaches may be useful, given that there is a consensus-based best practice standard. Evaluations of end-stage outcome may also be informed by long-term cohort studies in which the impact of lifestyle choices (such as participation in regular physical activity) is assessed.

Abbreviations: $\mathrm{HD}=$ Huntington disease; $\mathrm{JBI}=$ Joanna Briggs Institute.

To determine the level of evidence and the grade of recommendation of included studies, we used the JBI Levels of Evidence ${ }^{1}$ and JBI Grades of Recommendation. ${ }^{2}$

There were 6 pre/post-test control group studies addressing mobility and functional activities (level 2D). Four of these studies provided the intervention as part of an inpatient multidisciplinary program..$^{13,24,25,30}$ Clients were admitted for 3 weeks (intervention administered for 8 hours per day, 7 days a week) either once or 3 times per year. Studies that asked clients to return 3 times per year had higher dropout rates, with $60 \%-83 \%$ completing the intervention over 1-2 years. ${ }^{24,25,30}$ Mobility improved as measured by gait speed, Timed Up and Go (TUG) test, ${ }^{24,25}$ Tinetti performance oriented mobility assessment, ${ }^{13,30}$ and the physical performance test ${ }^{13}$ when assessed over a 1-year period. When the intervention was extended over 2 years, mobility (i.e., gait speed and TUG performance) did not decline. ${ }^{25}$ All studies administered multidisciplinary intervention; given the design and quality of the studies, it is difficult to conclude that physical therapy or any specific physical therapy intervention led to the improvements in mobility.

Two studies (level 2D) examined the impact of outpatient physical therapy on gait. ${ }^{11,23}$ Mirek et al. ${ }^{23}$ provided a proprioceptive neuromuscular facilitation-based intervention focused on gait and balance 3 times a week, 90 minutes per session. After 3 weeks, there was significant improvement in gait speed (measured by 10MWT) and mobility (measured by TUG and Tinetti Mobility Test). Bohlen et al. ${ }^{11}$ reported significant changes in spatiotemporal parameters of gait, gait speed, and TUG time following one-on-one physical therapy focused on gait and transfer training performed 2 times a week, 60 minutes a session for 6 weeks, as well as excellent adherence with overall attendance of $90 \%$ for physical therapy sessions. These studies support the effectiveness of one-on-one physical 
therapy focused on gait training to improve mobility. However, the findings are interpreted with caution, as both studies lacked adequate control groups.

The use of a rollator walker to improve gait parameters is supported by one single-session observational study without a control group (level 3E). ${ }^{22}$ Three weeks of gait training and seated exercises resulted in improvements in gait speed in a hospital-based study with no control group (level $3 \mathrm{E}){ }^{34}$ Finally, there is 1 case series (level 4C), examining the use of an outpatient group program to improve mobility. ${ }^{14}$ Three individuals ( 2 manifest and 1 premanifest) participated once a week in a 60-minute group program. A circuit training design was used with each exercise individualized to the client's skill level. All 3 individuals improved gait speed on the 10 MWT and TUG. These 2 studies provide insight into the potential benefits of individualized circuit training and support the need for future research in these areas.

\section{Action statement 3: Effectiveness of balance exercises in persons with HD}

Physical therapists may prescribe individualized exercises, including balance exercises, delivered at a moderate frequency and intensity to improve balance and balance confidence (evidence quality: 1,2 , and 4; recommendation strength: weak).

\section{Supporting evidence and clinical interpretation}

Ten studies ${ }^{11,12,14,21,23-26,29,33}$ examined the effects of exercise programs on clinical balance measures or balance confidence. Four of the 10 studies are classified as level $1 \mathrm{C}, 4$ as level 2D, and 2 as level 4C (table 3 ). Across the 10 studies, the most commonly used clinical balance outcome was the Berg Balance Scale $(n=7)$, followed by the Activities-specific Balance Confidence Scale $(n=4)$, Romberg test $(n=1)$, Functional Reach Test $(n=1)$, Pastor test $(n=1)$, and the four square step test $(n=1)$.

Intervention durations were 3 weeks, ${ }^{23} 6$ weeks, $^{11,21} 8$ weeks, ${ }^{14,26,33} 9$ weeks ( 3 weeks at 3 times a year for 12 months), ${ }^{24} 12$ weeks, ${ }^{12} 18$ weeks ( 3 weeks at 3 times a year for 24 months), ${ }^{25}$ and 9 months. ${ }^{29}$ The frequency of exercise ranged from 1 to 5 days per week performed in a variety of settings (outpatient clinic, inpatient rehabilitation hospital, community, and home).

Six of the 8 studies $^{11,14,23-25,33}$ included balance-related interventions such as mobility and skills training (i.e., sit-to-stand transfers, walking over soft surfaces, reaching, stair-climbing, and turning), progressive static and dynamic standing balance exercises (that is, narrowed and altered base of support, forward and side lunges, standing with eyes open and closed, standing without arm support, and balance reaction training. Four studies used aerobic and/or strengthening exercises. ${ }^{12,24,25,29}$ One study used task-specific training focused on walking, sit-tostand transfers, and standing. ${ }^{26}$ One study ${ }^{21}$ used supervised playing of the video game Dance Dance Revolution.

\section{Action statement 4: Effectiveness of breathing exercises in persons with HD}

Physical therapists may provide breathing exercises, including inspiratory and expiratory training, to improve respiratory muscle strength and cough effectiveness (evidence quality: $1 \mathrm{C}-\mathrm{D} ; 5 \mathrm{~B}$; recommendation strength: weak).

\section{Supporting evidence and clinical interpretation}

There is grade B evidence to support the use of respiratory training to improve respiratory function in persons with $\mathrm{HD}$. In a randomized controlled trial, Reyes et al. ${ }^{28}$ demonstrated that 4 months of progressive resistive inspiratory and expiratory training resulted in improved maximal inspiratory and expiratory pressures, as well as forced vital capacity and peak expiratory flow when compared with the control group, who completed fixed-resistance training.

In a pseudo-randomized controlled trial, Jones et al. ${ }^{18}$ produced similar findings, showing that 6 weeks of resisted inspiratory exercise resulted in improved sniff nasal inspiratory pressure and peak cough flow. The control group, who performed breathing exercises without resistance, also demonstrated improvements, suggesting that regular breathing exercises could improve pulmonary function in persons with $\mathrm{HD}$.

The expert opinion survey (level 5B) confirmed the results of these studies; $48.9 \%$ of clinicians treating individuals in the late-stage of $\mathrm{HD}$ reported use of respiratory exercises and specifically mentioned that their interventions included breathing exercises and use of an incentive spirometer. Many clinicians also reported interventions focused on posture and positioning for improved breathing, family and caregiver education on breathing exercises and chest clearance techniques, education on breathing techniques such as diaphragmatic and pursed-lip breathing, and collaboration with respiratory therapy and speech therapy.

\section{Action statement 5: Effectiveness of postural control training in persons with HD}

Physical therapists may prescribe an individually tailored program to improve postural control and may use positioning devices to optimize posture (evidence quality: $2 \mathrm{D}$; recommendation strength: weak).

\section{Supporting evidence and clinical interpretation}

There are 2 pretest-posttest (level 2D) studies, ${ }^{11,13}$ neither of which had a control group, to support physical therapy for secondary musculoskeletal and postural changes in people with $\mathrm{HD}$.

Training of postural control and stability over 12 sessions in an outpatient setting did not result in improvement in length and speed of center of mass projection, as measured by a force plate. ${ }^{11}$ In contrast, intensive inpatient multidisciplinary intervention (4 hours per day for 6 days a week), including 
exercises for postural alignment and stability, improved scores on the Tinetti Mobility Test. ${ }^{13}$ However, improvement in Tinetti scores could have been due to the cumulative effects of the multifactorial nature of the intervention, rather than the specific effect of postural alignment and stability training. Future work needs to examine the specific effect of postural training.

The consensus among experts was that intervention for secondary musculoskeletal and postural changes should be tailored to the stage of the disease. For instance, early in the disease focus can be on active exercises to improve core stability, muscle strengthening, fall prevention, functional exercises such as sit to stand, getting up from the floor, and posture correction. In the later stages of the disease, the focus of intervention shifts to practice of bed mobility, transfer training, and getting in and out of bed. A second major theme among experts was the use of positioning devices and supports to promote better posture and prevent secondary musculoskeletal changes. Examples of supports include wedge cushions, bolsters, pillows and bed railings for positioning in bed, and cushions or pillows for positioning in a wheelchair and the use of safety belt to prevent sliding. In the later stages of the disease, experts recommended use of specialized wheelchairs such as the Broda chair (Broda Seating, Chesterfield, MO) for optimal positioning (including flexible seat-back angle, supported footrest, pelvic belt, and antitipping devices for safety). Consensus also included educating caregivers on the use and operation of positioning devices and wheelchairs, as well as proper body mechanics for safe transfer of patients. Additional interventions that are used frequently but have not been formally investigated include stretching for contracture management and prevention, range of motion exercise, and specific positioning to encourage feeding and swallowing.

\section{Action statement 6: Role of physical therapy on ADL's, seating and positioning in late-stage care of persons with HD}

Physical therapists should ensure that care plans for individuals with $\mathrm{HD}$ with late-stage disease include appropriate positioning and seating, active movement, position, respiratory exercise, and education. Family and caregiver training to provide strategies for maintaining appropriate ongoing activity and participation for as long as possible is an important focus for the physical therapy team as part of late-stage care (evidence quality 5B, recommendation strength: expert opinion).

\section{Supporting evidence and clinical interpretation}

A literature search only revealed review or commentary articles that describe the application of best practice for late-stage care in other long-term conditions, and we recommend application of these principles in HD. Tarolli et al. ${ }^{38}$ describe their own care practices through 5 illustrative case examples related to $\mathrm{HD}$, caregiver burden, advance care planning, and end of life care. They conclude that it is critical for the multidisciplinary team to establish realistic goals and expectations and maintain a commitment to patient care preferences and quality of life.
In terms of nursing and rehabilitation care, ${ }^{39}$ tailored exercise programs and ongoing active engagement in goal-directed and social activities are critical to promote mood, motor function, and quality of life for as long as possible. Supporting evidence for these recommendations is summarized in Moskowitz and Rao, ${ }^{39}$ but is limited to 1 randomized trial of multisensory stimulation in late-stage $\mathrm{HD},{ }^{40} 2$ single-case studies ${ }^{41,42}$ on the role of hydrotherapy for advanced HD and a 14-week video-based exercise program, and 2 articles detailing social and gardening activities in inpatient settings.

Recommendations for late-stage care in $\mathrm{HD}$ focus on supporting activities of daily living, optimizing attention, posture, positioning, and seating, particularly during meal and postmeal times. In addition, there is focus on prevention of falls, analysis of previous falls, and development of midfall strategies to minimize injury risk. Experts specifically mentioned environmental modifications and seating adaptations to maximize posture and positioning. Additional treatments that are used frequently but have not been formally investigated include prevention of decubiti and airway clearance.

The expert opinion survey confirmed that identified in the review and expert commentary. Therapists reported that their focus was on facilitation of ongoing participation in activities that were achievable for the person with HD. An important element was family and caregiver training to maintain ongoing activity for as long as possible. Postural adaptations, positioning range of motion activities, and seating advice were regular recommendations. The importance of providing caregivers with strategies to encourage activity was highlighted. Last, the risk benefit balance of falls vs inactivity was pointed out by several experts.

\section{Limitations of recommendations}

There are several limitations to this guideline. The recommendations provided in this guideline are based on a small number of available studies, some of which lack control groups or use multidisciplinary interventions that limit our ability to interpret intervention effects. The studies have been graded by their level of evidence (table 3 ) to highlight these limitations. The heterogeneity of disease levels and stages across studies affects our ability to determine outcomes across disease stages. Finally, studies in languages other than English were not captured in our previously published review ${ }^{5}$ or this guideline; this could introduce language bias with respect to our results. To address this issue, we have gathered feedback from a wide range of professionals to provide a globally relevant guideline.

\section{Guideline implementation recommendations}

Many studies included in this review considered patient experiences, yielding important insights into how physical therapy interventions should be implemented in persons with $\mathrm{HD}$. Qualitative analyses suggest that individuals with $\mathrm{HD}$, 
their caregivers, and therapists perceive exercise as beneficial. The perceived benefits included physical benefits, such as improved gait and balance, ${ }^{17}$ social benefits, such as improved self-confidence, socialization, and a sense of community, ${ }^{17,36}$ and mental benefits, such as improved mindfulness and communication. $^{36}$

The evidence suggested that shared goal setting should be considered and that the influence of the caregiver should be a key factor to be explored during the initiation and implementation of exercise interventions. ${ }^{20}$ These recommendations build on previous work ${ }^{43}$ to develop a practice pathway for HD that can inform clinical assessment and intervention planning that is in line with the Guide to Physical Therapist's Patient/ Client Management Model (figure 2).

There may be a benefit for people with HD to receive targeted exercise interventions multiple times over a year or longer, rather than relatively short interventions (often 6-8 weeks) that are abruptly discontinued with minimal follow-up. A clinical trial is currently underway evaluating this model of care in individuals with early-mid stage HD. ${ }^{44}$ There is increasing recognition across neurologic diseases about the importance of strategies to maintain physical activity through the life course of the disease $e^{32,45-48}$ Indeed, research across neurologic conditions provides evidence that secondary prevention strategies are crucial to maintaining function and warding off impairments that are secondary to mobility restrictions. ${ }^{45}$ Although implementation of inpatient multidisciplinary programs, which require extended stays in hospital or rehabilitation centers, is currently not feasible in many countries, there is supporting evidence to suggest that such a model should be considered. Importantly, future work must include economic evaluation and the potential for such programs to maintain high quality years of living with the disease.

Overall, exercise can be tailored to enable participation by individuals with $\mathrm{HD}$ and to address $\mathrm{HD}$-specific impairments. The facilitators for exercise participation identified by patients and caregivers included individualized training plans and schedules, group therapy, cues to improve adherence, and involvement of a committed caregiver or contact person. ${ }^{17,20}$ Barriers to exercise participation included cognitive impairments, poor balance, and lack of motivation. ${ }^{17,20}$ Such barriers may affect success with rehabilitation; thus, it is important to maximize facilitators to exercise to ensure success and adherence.

Figure 2 Patient/client management for individuals with Huntington disease using the clinical practice guideline

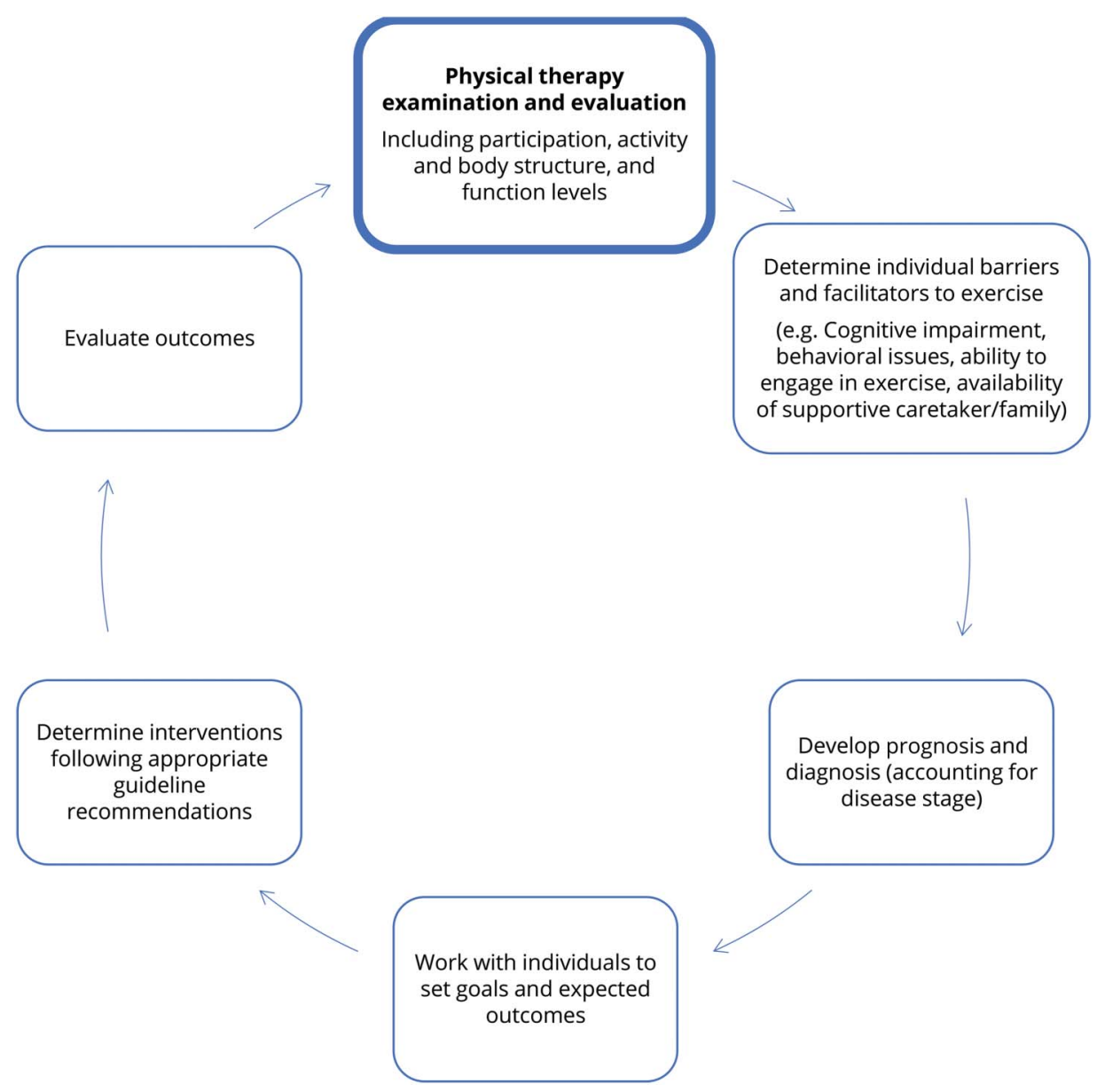


The following strategies may assist clinicians in implementing the guideline statements. Successful translation of this guideline to practice relies on clinician evaluation of their own practice environment and clinical skills to determine the best approach to implement the action statements.

1. Keep a copy of the exercise guidelines for individuals with HD (provided open access) in a convenient clinic location

2. Seek training specific to individuals with $\mathrm{HD}$ and recommended interventions

3. Build relationships with referral sources to encourage early referral of persons with $\mathrm{HD}$ to rehabilitation services

4. Identify a dedicated caregiver or family member to enhance uptake of exercise in the individual with HD

5. Individualize and tailor exercise training plans to each individual, using goal setting tools.

The guideline development group will evaluate the uptake of the guideline, including monitoring of guideline implementation leading to change in practice at the individual clinic level and monitoring of endorsements and awareness of the guideline in the broader HD community.

\section{Acknowledgment}

The authors gratefully acknowledge the individuals with HD who provided feedback on this document and the respondents to the survey for expert opinions for their insights and feedback. Guideline Development Group-Authors: M. Busse, N. E. Fritz, D. Kegelmeyer, A. Kloos, L. Quinn, A. K. Rao. Reviewers: Megan Danzl, PT, DPT, PhD, NCS; Katy Hamana, PT, PhD; Una Jones, PT, PhD; Elizabeth Ulanowski, PT, DPT, NCS; members of the EHDN Physiotherapy Working Group; and members of the HSG Rehabilitation Working Group. Advisors: Lavonne Goodman, MD; Martha Nance, MD; Judith Carrier, PhD, L. Hartel, Jane Harden, and all above-listed Reviewers.

\section{Study funding}

Study funded by the Huntington Study Group, European Huntington Disease Network, and the Griffith Foundation. All reviewers and advisors report no conflicts of interest relevant to this guideline. The guideline was developed independently and without influence of the funding agencies. No members of the guideline development group or advisors were part of funding decisions.

\section{Disclosure}

L. Quinn, D. Kegelmeyer, A. Kloos, and A. K. Rao received honorariums and travel expenses from the Huntington Study Group, European Huntington Disease Network, and Griffith Foundation related to this project. M. Busse reports no disclosures relevant to the manuscript. N. E. Fritz received honorariums and travel expenses from the Huntington Study Group, European Huntington Disease Network, and Griffith Foundation related to this project. Go to Neurology.org/N for full disclosures.

\section{Publication history}

Received by Neurology July 17, 2019. Accepted in final form November 8, 2019.

Appendix Authors

\begin{tabular}{|c|c|c|c|}
\hline Name & Location & Role & Contribution \\
\hline $\begin{array}{l}\text { Lori Quinn, } \\
\text { EdD, PT }\end{array}$ & $\begin{array}{l}\text { Teachers } \\
\text { College, } \\
\text { Columbia } \\
\text { University, New } \\
\text { York City }\end{array}$ & Author & $\begin{array}{l}\text { Interpreted the data } \\
\text { and drafted and } \\
\text { revised the manuscript } \\
\text { for intellectual content }\end{array}$ \\
\hline $\begin{array}{l}\text { Deb } \\
\text { Kegelmeyer, } \\
\text { MS, PT, DPT, } \\
\text { GCS }\end{array}$ & $\begin{array}{l}\text { The Ohio State } \\
\text { University, } \\
\text { Columbus }\end{array}$ & Author & $\begin{array}{l}\text { Interpreted the data } \\
\text { and drafted and } \\
\text { revised the manuscript } \\
\text { for intellectual content }\end{array}$ \\
\hline $\begin{array}{l}\text { Anne Kloos, } \\
\text { PhD, PT, NCS }\end{array}$ & $\begin{array}{l}\text { The Ohio State } \\
\text { University, } \\
\text { Columbus }\end{array}$ & Author & $\begin{array}{l}\text { Interpreted the data } \\
\text { and drafted and } \\
\text { revised the manuscript } \\
\text { for intellectual content }\end{array}$ \\
\hline $\begin{array}{l}\text { Ashwini K. Rao, } \\
\text { EdD, OTR/L, } \\
\text { FAOTA }\end{array}$ & $\begin{array}{l}\text { Columbia } \\
\text { University, New } \\
\text { York City }\end{array}$ & Author & $\begin{array}{l}\text { Interpreted the data } \\
\text { and drafted and } \\
\text { revised the manuscript } \\
\text { for intellectual content }\end{array}$ \\
\hline $\begin{array}{l}\text { Monica Busse, } \\
\text { BSc, BSc (Hons), } \\
\text { MSc (Med) PhD, } \\
\text { PT }\end{array}$ & $\begin{array}{l}\text { Cardiff } \\
\text { University, } \\
\text { Cardiff }\end{array}$ & Author & $\begin{array}{l}\text { Interpreted the data } \\
\text { and drafted and } \\
\text { revised the manuscript } \\
\text { for intellectual content }\end{array}$ \\
\hline $\begin{array}{l}\text { Nora E. Fritz, } \\
\text { PhD, PT, DPT, } \\
\text { NCS }\end{array}$ & $\begin{array}{l}\text { Wayne State } \\
\text { University, } \\
\text { Detroit }\end{array}$ & Author & $\begin{array}{l}\text { Chaired the Guideline } \\
\text { Development Group, } \\
\text { interpreted the data, } \\
\text { and drafted and } \\
\text { revised the manuscript } \\
\text { for intellectual content }\end{array}$ \\
\hline
\end{tabular}

\section{References}

1. New JBI Levels of Evidence. Adalaide: The Joanna Briggs Institute; 2014. Available at: joannabriggs.org/sites/default/files/2019-05/JBI-Levels-of-evidence_2014_0.pdf. Accessed June 7, 2019.

2. New JBI Grades of Recommendation. Adalaide: The Joanna Briggs Institute; 2014. Available at: joannabriggs.org/assets/docs/approach/JBI-Levels-of-evidence_2014. pdf. Accessed June 7, 2019.

3. Quinn L, Busse M, Broad M, et al. European Huntington's Disease Network: Physiotherapy Guidance Document for Physiotherapists, First Edition. Ulm: EHDN; 2009. Available at: euro-hd.net/html/network/groups/physio.

4. Varda E, Demetriou CA, Heraclides A, Christou YP, Zamba-Papanicolaou E. Quality of life of cypriot patients suffering with Huntington's disease. PLoS Curr 2016;8. doi: 10.1371/currents.hd.270776c4fdd7776499dd45bf47049a75.

5. Fritz NE, Rao AK, Kegelmeyer D, et al. Physical therapy and exercise interventions in Huntington's disease: a mixed methods systematic review. J Huntingtons Dis 2017;6: 217-235.

6. Quinn L, Busse M, Broad M, et al. Development of physiotherapy guidance and treatment-based classifications for people with Huntington's disease. Neurodegener Dis Manag 2012;2:11-19.

7. Quinn L, Busse M, Bunnig K, et al. Physiotherapy clinical guidelines for Huntington's disease. Neurodegener Dis Manag 2012;2:21-31.

8. Quinn L, Busse M, Carrier J, et al. Physical therapy and exercise interventions in Huntington's disease: a mixed methods systematic review protocol. JBI Database System Rev Implement Rep 2017;15:1783-1799.

9. The Joanna Briggs Institute Reviewers' Manual. Adalaide: The Joanna Briggs Institute; 2019. Available at: wiki.joannabriggs.org/display/MANUAL/Accessed June 7, 2019.

10. Joanna Briggs Collaboration. The Joanna Briggs Institute Website. Available at: joannabriggs.org/global_reach/collaboration. Accessed: June 3, 2019.

11. Bohlen S, Ekwall C, Hellström K, et al. Physical therapy in Huntington's diseasetoward objective assessments? Eur J Neurol 2013;20:389-393.

12. Busse $\mathrm{M}$, Quinn L, Debono K, et al. A randomized feasibility study of a 12 -week community-based exercise program for people with Huntington's disease. J Neurol Phys Ther 2013;37:149-158.

13. Ciancarelli I, Tozzi Ciancarelli MG, Carolei A. Effectiveness of intensive neurorehabilitation in patients with Huntington's disease. Eur J Phys Rehabil Med 2013;49: 189-195. 
14. Clark D, Danzl MM, Ulanowski E. Development of a community-based exercise program for people diagnosed and at-risk for Huntington's disease: a clinical report. Physiother Theory Pract 2016;3985:1-8.

15. Cruickshank TM, Thompson JA, Dom'inguez DJF, et al. The effect of multidisciplinary rehabilitation on brain structure and cognition in Huntington's disease: an exploratory study. Brain Behav 2015;5:e00312.

16. Dawes H, Collett J, Debono K, et al. Exercise testing and training in people with Huntington's disease. Clin Rehabil 2015;29:196-206.

17. Frich JC, Røthing M, Berge AR. Participants', caregivers', and professionals' experiences with a group-based rehabilitation program for Huntington's disease: a qualitative study. BMC Health Serv Res 2014;14:395.

18. Jones U, Busse M, Enright S, et al. Respiratory decline is integral to disease progression in Huntington's disease. Eur Respir J 2016;6:766-773.

19. Khalil H, Quinn L, van Deursen R, et al. What effect does a structured home-based exercise programme have on people with Huntington's disease? A randomized, controlled pilot study. Clin Rehabil 2013;27:646-658.

20. Khalil H, Quinn L, van Deursen R, Martin R, Rosser A, Busse M. Adherence to use of a home-based exercise DVD in people with Huntington disease: participants' perspectives. Phys Ther 2012;12:69-82.

21. Kloos AD, Fritz NE, Kostyk SK, Young GS, Kegelmeyer DA. Video game play (Dance Dance Revolution) as a potential exercise therapy in Huntington's disease: a controlled clinical trial. Clin Rehabil 2013;27:972-982.

22. Kloos A, Kegelmeyer D, Kostyk S. The effects of assistive devices on gait measures in Huntington's disease. PLoS One 2012;7:e30903.

23. Mirek E, Filip M, Banaszkiewicz K, et al. The effects of physiotherapy with PNF concept on gait and balance of patients with Huntington's disease-pilot study. Neurol Neurochir Pol 2015;49:354-357.

24. Piira A, van Walsem MR, Mikalsen G, Nilsen KH, Knutsen S, Frich JC. Effects of a one year intensive multidisciplinary rehabilitation program for patients with Huntington's disease: a prospective intervention study. PLoS Curr 2013:5.

25. Piira A, vanWalsem M, Mikalsen G, Øie L, Frich J, Knutsen S. Effects of a two-year intensive multidisciplinary rehabilitation program for patients with Huntington's disease: a prospective intervention study. PLoS Curr Huntingt Dis 2014;1.

26. Quinn L, Debono K, Dawes H, et al. Task-specific training in Huntington disease: a randomized controlled feasibility trial. Phys Ther 2014;94:1555-1568.

27. Quinn L, Hamana K, Kelson M, et al. A randomized, controlled trial of a multi-modal exercise intervention in Huntington's disease. Parkinsonism Relat Disord 2016;31: 46-52.

28. Reyes A, Cruickshank T, Nosaka K, Ziman M. Respiratory muscle training on pulmonary and swallowing function in patients with Huntington's disease: a pilot randomised controlled trial. Clin Rehabil 2015;29:961-973.

29. Thompson JA, Cruickshank TM, Penailillo LE, et al. The effects of multidisciplinary rehabilitation in patients with early-to-middle-stage Huntington's disease: a pilot study. Eur J Neurol 2013;20:1325-1329.

30. Zinzi P, Salmaso D, De Grandis R, et al. Effects of an intensive rehabilitation programme on patients with Huntington's disease: a pilot study. ClinRehabil 2007;21: $603-613$.
31. Frese S, Petersen JA, Ligon-Auer M, et al. Exercise effects in Huntington disease. J Neurol 2017;264:32-39.

32. Busse M, Quinn L, Drew C, et al. Physical activity self-management and coaching compared to social interaction in huntington disease: results from the ENGAGE-HD randomized, controlled pilot feasibility trial. Phys Ther 2017;97:625-639.

33. Fritz NE, Busse M, Jones K, Khalil H, Quinn L; Members of the Physiotherapy Working Group of the European Huntington's Disease Network. A classification system to guide physical therapy management in Huntington disease. J Neurol Phys Ther 2017;41:156-163.

34. Mirek E, Filip M, Dhwala W, et al. The influence of motor ability rehabilitation on temporal-spatial parameters of gait in Huntington's disease patients on the basis of a three-dimensional motion analysis system: an experimental trial. Neurol Neurochir Pol 2018;52:575-580.

35. Cruickshank TM, Reyes AP, Penailillo LE, et al. Effects of multidisciplinary therapy on physical function in Huntington's disease. Acta Neurol Scand 2018;138:500-507.

36. Ulanowski EA, Danzl M, Schwartz V, Reed C. A qualitative examination of physiotherapist led community-based yoga for individuals with Huntington's disease. Contemp Therapies Clin Pract 2017;28:146-151.

37. Porritt K, Gomersall J, Lockwood C. Study selection and critical appraisal. Am J Nurs 2014;114:47-52.

38. Tarolli CG, Chesire AM, Biglan KM. Palliative care in Huntington disease: personal reflections and a review of the literature. Tremor Other Hyperkinet Mov 2017;7:454.

39. Moskowitz CB, Rao AK. Making a measurable difference in advanced Huntington disease. Handb Clin Neurol 2017;144:183-196.

40. Leng TR, Woodward MJ, Stokes MJ, Swan AV, Wareing LA, Baker R. Effects of multisensory stimulation in people with Huntington's disease: a randomized controlled pilot study. Clin Rehabil 2003;17:30-41.

41. Sheaff F. Hydrotherapy in Huntington's disease. Nurs Times 1990;86:46-49.

42. Quinn L, Rao AK. Physical therapy for people with Huntington's disease: current perspectives and case report. J Neurol Phys Ther 2002;26:145-153.

43. Inbar N, Quinn L, Hamana K, Busse M. Functional screening for Huntington's disease: a phased approach. J Neurol Neurosur Ps 2016;87:A74.

44. Drew CJG, Quinn L, Hamana K, et al. Physical ACtivity and Exercise Outcomes in Huntington Disease (PACE-HD): protocol for a 12-month trial within cohort evaluation of a physical activity intervention in people with Huntington disease. Phys Ther 2019;99:1201-1210.

45. Quinn L, Morgan D. From disease to health: physical therapy health promotion practices for secondary prevention in adult and pediatric neurologic populations. J Neurol Phys Ther 2017;41:S46-S54.

46. Dobkin BH. Behavioral self-management strategies for practice and exercise should be included in neurologic rehabilitation trials and care. Curr Opin Neurol 2016;29:693-699.

47. Ellis T, Motl R. Physical activity behavior change in persons with neurologic disorders: overview and examples from Parkinson disease and multiple sclerosis. J Neurol Phys Ther 2013;37:85-90

48. Hamana K, Gambling T, Quinn L, Busse M. Development of theoretically underpinned physical activity interventions for Huntington's disease. J Neurol Neurosurg Psychiatry 2018;89:A101

\section{Apply for the 2020 Palatucci Advocacy Leadership Program}

The $18^{\text {th }}$ annual Palatucci Advocacy Leadership Forum will take place July 23-26, 2020, at the Hyatt Tamaya Resort in Albuquerque, NM. The Academy desires to help applicants who have a clear passion, strong leadership potential, and an idea on how to advocate on behalf of their patients, community, or profession. The Palatucci Advocacy Leadership Forum will teach you how to:

- Turn your needs and those of your patients into action plans

- Develop media communication skills, whether in front of the camera or through written editorials

- Build and maintain relationships with reporters

- Represent your patients and profession with state and federal representatives

If you see problems or opportunities in your institution, local community, or on a state/national level that you want to address, learn more and apply by the March 9 deadline at AAN.com/view/PALF. 


\section{Neurology}

\section{Clinical recommendations to guide physical therapy practice for Huntington disease}

Lori Quinn, Deb Kegelmeyer, Anne Kloos, et al.

Neurology 2020;94;217-228 Published Online before print January 6, 2020

DOI 10.1212/WNL.0000000000008887

This information is current as of January 6,2020

\begin{tabular}{|c|c|}
\hline $\begin{array}{l}\text { Updated Information \& } \\
\text { Services }\end{array}$ & $\begin{array}{l}\text { including high resolution figures, can be found at: } \\
\text { http://n.neurology.org/content/94/5/217.full }\end{array}$ \\
\hline References & $\begin{array}{l}\text { This article cites } 41 \text { articles, } 2 \text { of which you can access for free at: } \\
\text { http://n.neurology.org/content/94/5/217.full\#ref-list-1 }\end{array}$ \\
\hline Citations & $\begin{array}{l}\text { This article has been cited by } 1 \text { HighWire-hosted articles: } \\
\text { http://n.neurology.org/content/94/5/217.full\#\#otherarticles }\end{array}$ \\
\hline Subspecialty Collections & $\begin{array}{l}\text { This article, along with others on similar topics, appears in the } \\
\text { following collection(s): } \\
\text { All Rehabilitation } \\
\text { http://n.neurology.org/cgi/collection/all_rehabilitation } \\
\text { Huntington's disease } \\
\text { http://n.neurology.org/cgi/collection/huntingtons_disease }\end{array}$ \\
\hline Permissions \& Licensing & $\begin{array}{l}\text { Information about reproducing this article in parts (figures,tables) or in } \\
\text { its entirety can be found online at: } \\
\text { http://www.neurology.org/about/about_the_journal\#permissions }\end{array}$ \\
\hline Reprints & $\begin{array}{l}\text { Information about ordering reprints can be found online: } \\
\text { http://n.neurology.org/subscribers/advertise }\end{array}$ \\
\hline
\end{tabular}

Neurology ${ }^{\circledR}$ is the official journal of the American Academy of Neurology. Published continuously since 1951, it is now a weekly with 48 issues per year. Copyright Copyright ( 2020 The Author(s). Published by Wolters Kluwer Health, Inc. on behalf of the American Academy of Neurology.. All rights reserved. Print ISSN: 0028-3878. Online ISSN: 1526-632X.

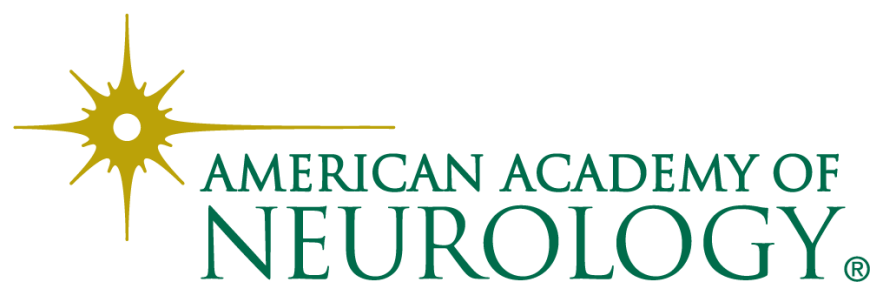

